\title{
First evaluation of bendiocarb in experimental huts using different substrates in Madagascar
}

Sanjiarizaha Randriamaherijaona ${ }^{1,2^{*}}$, Thiery Nepomichene ${ }^{1,2}$, Jade Assoukpa ${ }^{1,3}$, Yoann Madec $^{3}$ and Sébastien Boyer ${ }^{1}$

\begin{abstract}
Background: Indoor residual spraying with insecticide is recommended for malaria control in high-transmission settings. Determination of residual activity of insecticides is essential for the selection of appropriate indoor spraying policy. The present study was undertaken to evaluate the residual effect of bendiocarb, a carbamate insecticide used in Madagascar, on different indoor surfaces in order to elaborate future vector control interventions.
\end{abstract}

Methods: The residual activity of bendiocarb was evaluated in both experimental huts and houses. Tests in experimental huts on different substrates represented a small scale-field trials. The houses IRS performed in parallel of experimental huts IRS, was done to compare semi-field results and field results. Bioassays according to the World Health Organization (WHO) standard protocol were carried out on different substrates impregnated with bendiocarb using susceptible strains of Anopheles arabiensis and Aedes albopictus.

Results: Bendiocarb induced significantly high mortality in treated huts against exposed mosquito $(p<0.005)$ compared to untreated huts. The mortality is up to the WHO threshold of $80 \%$ during 5 months post-treatment. Using a multivariate analysis, Ae. albopictus mortality decreased significantly from the 3rd month post-treatment. However, An. arabiensis mortality decreased significantly from the 4 th month after treatment. Comparing mosquito mortality results from the mud experimental huts and the mud houses showed no significant difference regarding the persistence of bendiocarb on wall.

Conclusions: Current data suggest variable persistence of bendiocarb according to the type of wall surfaces, highlighting the importance of testing insecticide for IRS in local context before using them in large scale. Data from this study validate also the importance of using experimental huts as representative tool to evaluate the effectiveness of an insecticide.

Keywords: Bendiocarb, Residual activity, Bioassay, Carbamate, Insecticide, Madagascar, Anopheles arabiensis, Aedes albopictus, malaria vector

\section{Background}

An efficient control of vector species is central in malaria eradication policy [1]. Indoor residual spraying (IRS) formed the mainstay of the vector control activities in the southern African sub-region. Initially, IRS

\footnotetext{
*Correspondence: sanji@pasteur.mg

1 Unité d'Entomologie Médicale, Institut Pasteur de Madagascar,

BP 1274, Antananarivo, Madagascar

Full list of author information is available at the end of the article
}

was considered useful for malaria prevention in areas with low-to-moderate transmission, whereas insecticide-treated nets (ITNs) were considered as suitable in high endemic areas [2]. Operational scale malaria vector control using IRS and ITNs has been implemented extensively in most malaria endemic countries [3, 4]. Pyrethroids are the most commonly used insecticides for net impregnation due to their efficacy, fast acting effect at low dose and low toxicity for mammals [5]. 
The implementation of insecticide resistance management strategies is necessary to avoid their development in malaria vectors which may compromise the success of vector control, and to preserve the efficacy of used insecticides [6]. Currently, the IRS efficacy of contemporary insecticides recommended by the World Health Organization (WHO) is highly variable. Although dichlorodiphenyltrichloroethane (DDT) is both long-lasting and cost-effective [7]. However, organophosphates, carbamates, and pyrethroids that are ideal for IRS are mostly shorter-lived and more expensive.

Actually, carbamates are effective insecticides to control malaria vectors in pyrethroid-DDT resistance areas, mainly because of its different mode of action, and no cross- or multiple-resistances are reported until now. In Benin, a decrease of malaria transmission was observed in the months following a large-scale IRS campaign using the carbamate insecticide bendiocarb, protecting more than 350,000 peoples $[8,9]$. In the Gambia, mosquito house entry, estimated by light traps, was significantly lower in houses sprayed by bendiocarb than in unsprayed houses [10]. Regarding this proved efficacy of bendiocarb, the Malagasy Republic adopted a national malaria control strategy based on large-scale integrated control measures with IRS of bendiocarb since 2009. Previous studies reported that residual life of an insecticide depends on the substrate on which it is applied $[11,12]$.

In the present study, a monthly following of bendiocarb residual activity was conducted to investigate its residual life on different substrates. This study performed with sensitive Anopheles and Aedes strains was carried out under small scale-field conditions in experimental huts and in field conditions in inhabited houses to compare the semi-field and field results.

\section{Methods}

\section{Biological materials for insecticide residual activity monitoring}

Two laboratory strains were used for all insecticide tests: Anopheles arabiensis and Aedes albopictus. Those strains were respectively established in January 2008 and in April 2010 at Institut Pasteur de Madagascar. Those colonies were characterized in the laboratory for insecticide susceptibility using standard WHO impregnated paper tests: $100 \%$ mortality was observed with DDT, fenitrothion, propoxur, permethrin, deltamethrin and bendiocarb. No $k d r$ or ace-1 resistance gene was detected by PCR in $A n$. arabiensis.

\section{Study sites and substrates treated}

Located on the eastern edge of the Malagasy Central highlands, villages of Saharevo (S18 $51^{\prime} 12.9^{\prime \prime}$ E48 $07^{\prime} 48.8^{\prime \prime}$ ) and Ambohitranivo (S18 50'52.71
E48 $8^{\circ} 4^{\prime} 24.17^{\prime \prime}$ ) are located in the Moramanga district, Madagascar. Ten experimental huts were built with different wall type representing the different habitat types in Madagascar (walls made of cement, wood, tin, mud and vegetal materials). Each hut type was duplicated, one being the control hut and the other the treated hut (Fig. 1).

\section{Insecticide and insecticide treatment}

A wettable powder formulation of bendiocarb (80 WP Ficam $\left.{ }^{\circledR}\right)$ provided by the Malagasy National Malaria Control Programme (NMCP) was used. This insecticide is an irreversible acetylcholinesterase inhibitor acting on the insect central nervous system [13]. Bendiocarb WP $80 \%$ is among the 12 insecticides recommended by WHO for indoor residual spraying against malaria vectors with residual activity estimated to 6 months [14]. It was used at the WHO recommended dose of $80 \%$ ( $0.4 \mathrm{~g} /$ $\mathrm{m}^{2}$ ). The spraying was performed by qualified NMCP's agents according to WHO recommendations [15].

The spraying of the experimental huts was performed in one day at the end of July 2013, at the middle of the dry season after 2 months of bioassay with no insecticide, acting as a control period. It also allows that the experimental huts are not contaminated by insecticides [7]. The same day, fifteen randomly chosen houses per village were also sprayed. The insecticide treatment was performed under similar conditions. All experiment measurements were performed (in experimental huts and in houses) from June 2013 to February 2014.

\section{Residual activity of insecticide treatment}

The evaluation of insecticide treatment started 1 month after treatment and ran for 7 months from August 2013 to February 2014. WHO cone bioassay test was undertaken in every hut and house walls to evaluate the residual activity of the insecticide. Every month, 10 3-5 day-old females of An. arabiensis or Ae. albopictus were introduced into each cone. One cone was fixed to each face of wall per hut for $30 \mathrm{~min}$ exposure according to WHO guidelines [7], thus a total replicate of four cones were used per house. Then, mosquitoes were transferred into a small plastic cup for holding. $10 \%$ sugar solution was provided during the $24 \mathrm{~h}$ holding period at $25^{\circ} \mathrm{C}$ and $80 \%$ relative humidity in the insectarium. After $24 \mathrm{~h}$, alive and dead mosquitoes were recorded.

\section{Data analysis}

The unit of all statistical analyses was the cone. In the experimental huts, two sites, during 9 months, with 10 huts and four cones per hut lead to 720 units of measurement; 440 were observed without treatment, and 280 with treatment. In houses, during 9 months, with 22 houses 


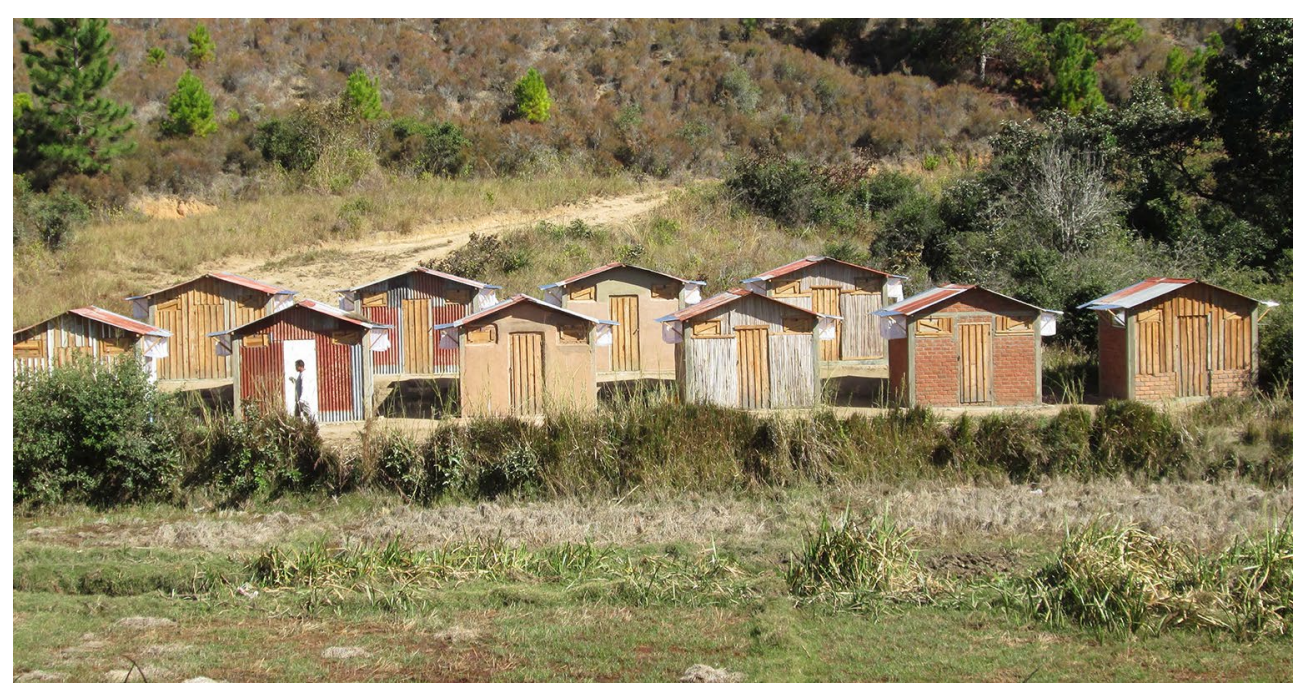

Fig. 1 Experimental huts. Saharevo station

with four cones in each house lead to 792 units of measurement; 176 without treatment and 616 with treatment. Of the 15 houses from each site, 10 and 12 were in mud and only those were retained in the analysis. All analysis was conducted separately for each mosquito species.

Mortality was defined as the proportion of mosquitoes who had died per statistical unit, and was described using median, inter-quartile range (IQR) and range. Comparisons between treated and untreated huts on the one hand, and treated and untreated houses on the other hand were conducted using the Wilcoxon or Kruskal-Wallis non parametric tests, as distributions were not Gaussian. Overall comparisons, and comparison after controlling for site, type of wall, or month were performed.

Treatment is considered effective if it leads to a mortality of at least $80 \%$. Each unit was then defined based on his threshold, and a logistic regression model was implemented to evaluate whether the type of wall modified the effect of the treatment, and if the effect of treatment faded with time (tested using interactions). In order to account for repeated measurements on similar units (hut or house), random effects were introduced. Statistical analysis were performed using $\mathrm{R}$ [16].

\section{Results}

A total of 3024 bioassays were performed during 9 months of follow-up using 15,120 females of An. arabiensis and 15,120 females of Ae. albopictus. For each species, 616 measurements were carried out on untreated walls (440 in experimental huts and 176 in houses) and 896 measurements on treated walls (280 in experimental huts and 616 houses).
When restricting the analysis to untreated huts, mortality was similarly low whatever the type of walls both in An. arabiensis and Ae. albopictus. The mortality rates recorded were always below $5 \%$ (average $=2.6 \%$ ).

For both mosquito species, in experimental huts, the insecticide treatment on walls increased significantly the mosquito mortality rate $(\mathrm{p}<0.0001)$ regardless of the type of wall and the time to treatment (Tables 1,2). For An. arabiensis, the mortality rate was $98-100 \%$ during 3 months post-treatment on different treated substrates. From the 4th to the 7th month, induced mortality ranged from $16 \%$ (wall made of mud) to $100 \%$ (wall made of wood), indicating a difference in the persistence of insecticide based on treated substrate (Fig. 2). Regarding bioassay with Ae. albopictus based on wall type, mortality rate is up to $80 \%$ (WHO threshold validity) during three months when bendiocarb is applied on mud wall. Aedes albopictus mortality breaks through the threshold of $80 \%$ after the 4th, the 5th, the 6th and the 7th months posttreatment respectively for cement, vegetal materials, tin and wood wall types (Fig. 3).

The multivariate model showed that the induced mortality of An. arabiensis, when compared to wood, is largely reduced when the treatment is sprayed on a porous surface like cement or mud (odds ratio (OR) [95\% confidence interval $(\mathrm{CI})]: 0.2$ [0.1-0.3] and 0.2 [0.1-0.6], respectively); it is reduced but more modestly when sprayed on tin substrate (OR (95\% CI]: $0.4[0.2-0.6])$. In Ae. albopictus, as compared to wood, induced mortality of the insecticide is even more greatly reduced in cement and mud surface (OR [95\% CI]: 0.07 [0.04-0.1] and $0.005[0.03-0.1]$, respectively); and more modestly reduced when sprayed on tin substrate (OR [95 \% CI]: 
Table 1 Univariate analysis of induced mortality against An. arabiensis in experimental huts

\begin{tabular}{|c|c|c|c|c|c|c|c|}
\hline \multirow[t]{2}{*}{ Variables } & \multicolumn{3}{|c|}{ Untreated huts } & \multicolumn{3}{|c|}{ Treated huts } & \multirow[t]{2}{*}{$p$ value } \\
\hline & $\mathbf{N}$ & $\begin{array}{l}\text { Median [IQR] } \\
\text { [IQR] }\end{array}$ & [Min-max] & $\mathbf{N}$ & \multicolumn{2}{|l|}{ [IQR] } & \\
\hline Treatment & 440 & $0.0[0.0-0.0]$ & {$[0.0-1.0]$} & 280 & $1.0[0.7-1.0]$ & {$[0.0-1.0]$} & $<2.010^{-16}$ \\
\hline \multicolumn{8}{|l|}{ Site } \\
\hline Ambohitranivo & 220 & $0.0[0.0-0.0]$ & {$[0.0-0.3]$} & 140 & $1.0[0.8-1.0]$ & {$[0.0-1.0]$} & $<2.010^{-16}$ \\
\hline Saharevo & 220 & $0.0[0.0-0.0]$ & {$[0.0-1.0]$} & 140 & $1.0[0.7-1.0]$ & {$[0.1-1.0]$} & $<2.010^{-16}$ \\
\hline \multicolumn{8}{|l|}{ Wall type } \\
\hline Wood & 88 & $0.0[0.0-0.0]$ & {$[0.0-0.1]$} & 56 & $1.0[1.0-1.0]$ & {$[0.5-1.0]$} & $<2.010^{-16}$ \\
\hline Cement & 88 & $0.0[0.0-0.0]$ & {$[0.0-0.2]$} & 56 & $1.0[0.3-1.0]$ & {$[0.0-1.0]$} & $<2.010^{-16}$ \\
\hline Vegetal materials & 88 & $0.0[0.0-0.0]$ & {$[0.0-0.3]$} & 56 & $1.0[0.9-1.0]$ & {$[0.2-1.0]$} & $<2.010^{-16}$ \\
\hline Tin & 88 & $0.0[0.0-0.0]$ & {$[0.0-0.2]$} & 56 & $1.0[0.7-1.0]$ & {$[0.1-1.0]$} & $<2.010^{-16}$ \\
\hline Mud & 88 & $0.0[0.0-0.0]$ & {$[0.0-1.0]$} & 56 & $0.9[0.3-1.0]$ & {$[0.0-1.0]$} & $<2.010^{-16}$ \\
\hline \multicolumn{8}{|l|}{ Month } \\
\hline June & 80 & $0.0[0.0-0.0]$ & {$[0.0-0.3]$} & 0 & - & - & - \\
\hline July & 80 & $0.0[0.0-0.0]$ & {$[0.0-0.2]$} & 0 & - & - & - \\
\hline August & 40 & $0.0[0.0-0.0]$ & {$[0.0-0.1]$} & 40 & $1.0[1.0-1.0]$ & {$[0.9-1.0]$} & $<2.010^{-16}$ \\
\hline September & 40 & $0.0[0.0-0.0]$ & {$[0.0-0.1]$} & 40 & $1.0[1.0-1.0]$ & [0.9-1.0] & $<2.010^{-16}$ \\
\hline October & 40 & $0.0[0.0-0.1]$ & {$[0.0-0.2]$} & 40 & $1.0[1.0-1.0]$ & {$[0.8-1.0]$} & $<2.010^{-16}$ \\
\hline November & 40 & $0.0[0.0-0.1]$ & {$[0.0-0.1]$} & 40 & $1.0[0.9-1.0]$ & {$[0.1-1.0]$} & $2.610^{-14}$ \\
\hline December & 40 & $0.0[0.0-0.1]$ & {$[0.0-0.1]$} & 40 & $1.0[0.9-1.0]$ & {$[0.2-1.0]$} & $2.510^{-15}$ \\
\hline January & 40 & $0.0[0.0-0.1]$ & {$[0.0-0.1]$} & 40 & $0.7[0.3-0.8]$ & {$[0.0-1.0]$} & $1.010^{-13}$ \\
\hline February & 40 & $0.0[0.0-0.0]$ & {$[0.0-0.2]$} & 40 & $0.3[0.2-0.5]$ & {$[0.0-1.0]$} & $2.510^{-14}$ \\
\hline
\end{tabular}

$0.2[0.1-0.4]$ ) or on vegetal materials (OR [95 \% CI]: 0.5 [0.3-0.8]).

Using the same multivariate model and regardless of the type of pulverized substrate, mortality of An. arabiensis decreased significantly from the 4th month after treatment $\left(\mathrm{OR}=1.910^{-3}\left[\begin{array}{lll}8.8 & 10^{-5}-4.0 & 10^{-2}\end{array}\right]\right)$. For $A e$. albopictus, a significative decrease of mosquito mortality is observed from the 3rd month post treatment $\left(\mathrm{OR}=2.910^{-3}\left[3.110^{-4}-2.710^{-2}\right]\right)$ (Table 3).

In houses, for An. arabiensis and Ae. albopictus, the lethal effect of the insecticide increased significantly compared to control houses without insecticide spraying $(\mathrm{p}<0.005)($ Tables 4,5$)$. As expected, mortality rates decreased over time $(\mathrm{p}<0.05)$. For An. arabiensis, the mortality rate decreased from 100 to $85 \%$ until the 5th month after treatment and drop from 70 to $30 \%$ at the 6th and 7th months (Fig. 4). For Ae. albopictus, mortality rate decrease from 100 to $87 \%$ during 4 months. At the 5th month, the mortality decreased from 75 to $45 \%$ at the 9th month (Fig. 5).

In Ambohitranivo and in Saharevo, respectively 93.3 and $86.6 \%$ of house's wall were made of mud. Comparison of mortality rate in mud experimental huts and mud houses showed no significant difference for the first few months, and then the mortality is significantly higher in houses then in experimental huts (Tables 6, 7). In both conditions, the mortality of Anopheles is up to $80 \%$ from the first to the 5 th month post-treatment. It is less than $80 \%$ for the 6 th and 7 th months.

\section{Discussion}

In the present study, the persistency of insecticide, estimated by observed An. arabiensis and Ae. albopictus mortality, depended on the type of wall substrate and the time elapsed since the insecticide spraying [17]. Indeed, in addition to enabling the assessment of bio-efficacy and residual activity, the wall bioassays also highlighted how differences in treatment surface substrates can affect insecticidal efficacy. That is to say, efficacy of active ingredients on mosquitoes is modulated by type of substrate onto which the compound is applied [12].

The variation of the residual life of the bendiocarb according to the surface treated observed in the present study also confirms previous observations [11, 12]. As in the present study, Ficam had a good residual activity during five months on both vegetal materials and mud in experimental huts [18]. Bioassay carried out by Ansari et al. [11] in India revealed a persistence of bendiocarb 
Table 2 Univariate analysis of induced mortality against Aedes albopictus in experimental huts

\begin{tabular}{|c|c|c|c|c|c|c|c|}
\hline \multirow[t]{3}{*}{ Variables } & \multicolumn{3}{|c|}{ Untreated huts } & \multicolumn{3}{|c|}{ Treated huts } & \multirow[t]{3}{*}{$p$ value } \\
\hline & $\mathbf{N}$ & Median [IQR] & [Min-Max] & $\mathbf{N}$ & Median [IQR] & [Min-max] & \\
\hline & & \multicolumn{2}{|l|}{ [Q1-Q3] } & & \multicolumn{2}{|l|}{ [Q1-Q3] } & \\
\hline Treatment & 440 & $0.0[0.0-0.0]$ & {$[0.0-0.3]$} & 280 & $1.0[0.7-1.0]$ & {$[0.0-1.0]$} & $<2.210^{-16}$ \\
\hline \multicolumn{8}{|l|}{ Site } \\
\hline Ambohitranivo & 220 & $0.0[0.0-0.0]$ & {$[0.0-0.3]$} & 140 & $0.9[0.7-1.0]$ & {$[0.0-1.0]$} & $<2.210^{-16}$ \\
\hline Saharevo & 220 & $0.0[0.0-0.0]$ & {$[0.0-0.3]$} & 140 & $1.0[0.7-1.0]$ & {$[0.0-1.0]$} & $<2.210^{-16}$ \\
\hline \multicolumn{8}{|l|}{ Wall type } \\
\hline Wood & 88 & $0.0[0.0-0.0]$ & {$[0.0-0.3]$} & 56 & $1.0[1.0-1.0]$ & {$[0.7-1.0]$} & $<2.210^{-16}$ \\
\hline Cement & 88 & $0.0[0.0-0.0]$ & {$[0.0-0.2]$} & 56 & $0.8[0.3-1.0]$ & {$[0.0-1.0]$} & $<2.210^{-16}$ \\
\hline Vegetal materials & 88 & $0.0[0.0-0.0]$ & {$[0.0-0.2]$} & 56 & $1.0[0.9-1.0]$ & [0.4-1.0] & $<2.210^{-16}$ \\
\hline Tin & 88 & $0.0[0.0-0.0]$ & {$[0.0-0.2]$} & 56 & $1.0[0.7-1.0]$ & {$[0.0-1.0]$} & $<2.210^{-16}$ \\
\hline Mud & 88 & $0.0[0.0-0.0]$ & {$[0.0-0.3]$} & 56 & $0.7[0.2-1.0]$ & {$[0.0-1.0]$} & $<2.210^{-16}$ \\
\hline \multicolumn{8}{|l|}{ Month } \\
\hline June & 80 & $0.0[0.0-0.0]$ & {$[0.0-0.1]$} & 0 & - & - & - \\
\hline July & 80 & $0.0[0.0-0.0]$ & {$[0.0-0.2]$} & 0 & - & - & - \\
\hline August & 40 & $0.0[0.0-0.0]$ & {$[0.0-0.2]$} & 40 & $1.0[1.0-1.0]$ & {$[0.9-1.0]$} & $<2.210^{-16}$ \\
\hline September & 40 & $0.0[0.0-0.0]$ & {$[0.0-0.1]$} & 40 & $1.0[1.0-1.0]$ & [0.9-1.0] & $<2.210^{-16}$ \\
\hline October & 40 & $0.0[0.0-0.1]$ & {$[0.0-0.3]$} & 40 & $0.9[0.8-1.0]$ & {$[0.6-1.0]$} & $4.910^{-15}$ \\
\hline November & 40 & $0.0[0.0-0.1]$ & {$[0.0-0.2]$} & 40 & $0.9[0.8-1.0]$ & {$[0.5-1.0]$} & $2.510^{-14}$ \\
\hline December & 40 & $0.0[0.0-0.1]$ & {$[0.0-0.1]$} & 40 & $0.9[0.6-1.0]$ & {$[0.1-1.0]$} & $5.510^{-12}$ \\
\hline January & 40 & $0.0[0.0-0.1]$ & {$[0.0-0.3]$} & 40 & $0.5[0.1-1.0]$ & {$[0.0-1.0]$} & $3.210^{-6}$ \\
\hline February & 40 & $0.0[0.0-0.0]$ & {$[0.0-0.2]$} & 40 & $0.4[0.1-0.7]$ & {$[0.0-1.0]$} & $5.710^{-9}$ \\
\hline
\end{tabular}

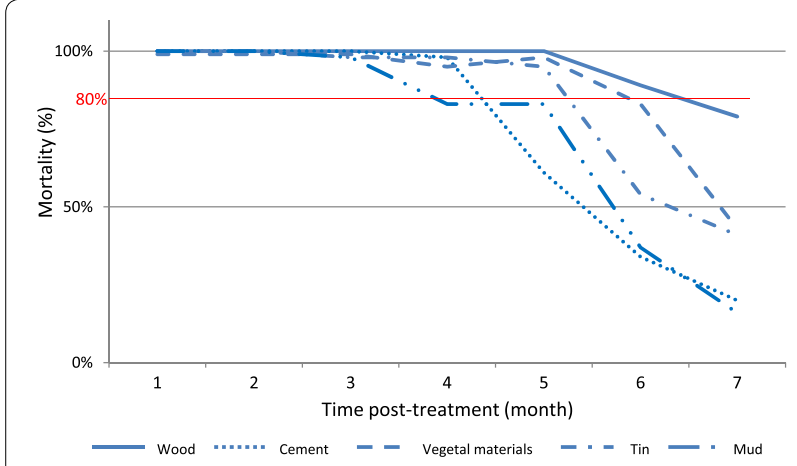

Fig. 2 Persistence of bendiocarb on different walls in experimental huts against An. arabiensis

against Anopheles culicifacies at $100 \%$ mortality for about 10 weeks on mud whereas Mpofu et al. [18] in Zimbabwe showed that bendiocarb provided $74 \%$ of $A n$. arabiensis mortality up to 5 months after spray on mud $[11,18]$. In Cameroon, Etang and colleagues reported that 13 weeks after spray on mud, the estimated efficacy of bendiocarb in terms of Anopheles gambiae s.s. killing was $80 \%$ [12]. As observed in Mozambique, there were no significant differences in mortality of An. arabaiensis evaluated on various porous substrates: mud and cement wall [19]. A similar study in the Philippines [20] found that bendiocarb provided between 75 and $100 \%$ mortality of Anopheles flavirostris during the first 3 months post-spray. However, these authors did not specify the surface type onto which the insecticide was sprayed. In Zimbabwe, Mpofu et al. [18] showed that bendiocarb provided a post-spray mortality of $74 \%$ on mud with up to $100 \%$ compared on vegetal materials, 5 months after the initial spray.

Bendiocarb WP showed shorter persistence (3 months) when applied to mud walls. One of the main reasons for the loss of insecticide activity may be the fast absorption by porous surfaces. Mud surfaces are very porous and the application of alkaline substances may degrade the molecule of the insecticide faster [21]. This residual life of bendiocarb is upper than that observed on mud in others studies. For instance, mud surfaces can be highly porous and adsorptive to insecticides, and substrates containing alkaline substances may degrade the candidate insecticide faster than substrates without alkaline contents [12].

A drastic drop in mortality was observed after 4 month in both the Iran and the present trial. From the results 


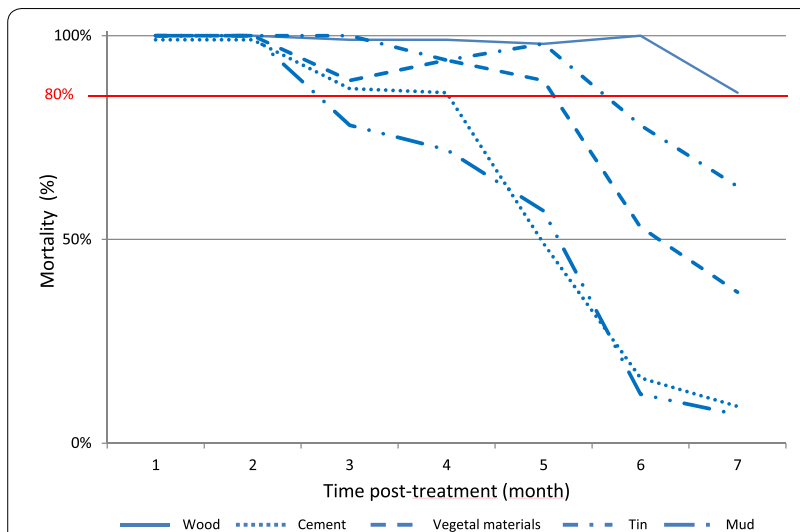

Fig. 3 Persistence of bendiocarb on different walls in experimental huts against Aedes albopictus

of the present study and that in Iran, it appears that the duration of insecticide activity is somewhat more prolonged on vegetal materials than on mud walls. Sprayed on a cement wall, bendiocarb decayed in less than 4 months, showing a short-life but was still considered as a promising insecticide to control resistant vectors as in Benin and in Tanzania [22, 23] Akogbeto et al. [11] suggested that a micro-encapsulation formulation of bendiocarb would make it last longer on treated surfaces. After 4 months experiment of indoor residual spraying treatments in experimental huts in Benin, bendiocarb was shown to be effective in controlling pyrethroid-resistant Anopheles, [24]. The useful life of bendiocarb does not exceed 6 months when sprayed on cement-plastered or mud surfaces [19].

Based on present data, as the spray deposits become progressively older, this irritability became less marked and led to mosquito mortalities up to $80 \%$, so the spraying cycles may not exceed 20 weeks for bendiocarb WP on mud walls while it may last 20 weeks at least for the others types of surfaces.

Based on percentage of mortalities observed in the bioassays, where contact between mosquitoes and sprayed

Table 3 Multivariate analysis of induced mortality against susceptible mosquito strains in experimental huts (mixed effect logistic regression)

\begin{tabular}{|c|c|c|c|c|c|}
\hline \multicolumn{2}{|l|}{ Species } & \multicolumn{2}{|l|}{ An. arabiensis } & \multicolumn{2}{|l|}{ Ae. albopictus } \\
\hline Variables & $\mathbf{N}$ & Adjusted OR [Cl $95 \%$ ] & $p$ value & Adjusted OR [Cl $95 \%$ ] & $p$ value \\
\hline \multicolumn{6}{|l|}{ Treatment } \\
\hline No & 440 & 1 & & 1 & \\
\hline Yes & 280 & $1.610^{5}\left[1.110^{4}-2.610^{6}\right]$ & $10^{-15}$ & $1.310^{5}\left[1.610^{4}-1.110^{6}\right]$ & $2.210^{-16}$ \\
\hline \multicolumn{6}{|l|}{ Wall type } \\
\hline Wood & 144 & 1 & & 1 & \\
\hline Cement & 144 & $0.2[0.1-0.3]$ & $10^{-6}$ & $0.07[0.04-0.1]$ & $1.110^{-12}$ \\
\hline Vegetal materials & 144 & $0.6[0.3-0.9]$ & 0.03 & $0.5[0.3-0.8]$ & 0.005 \\
\hline Tin & 144 & $0.4[0.2-0.6]$ & $10^{-3}$ & $0.2[0.1-0.4]$ & $2.6610^{-6}$ \\
\hline Mud & 144 & $0.2[0.1-0.6]$ & $10^{-3}$ & $0.05[0.03-0.1]$ & $4.410^{-16}$ \\
\hline \multicolumn{6}{|l|}{ Month } \\
\hline August & 40 & 1 & & 1 & 0.10 \\
\hline September & 40 & $0.9[0.1-14.2]$ & 0.95 & $0.2[0.0-1.4]$ & 0.01 \\
\hline October & 40 & $10.6[1.5-72.8]$ & 0.02 & $5.4[1.5-19.6]$ & 0.06 \\
\hline November & 40 & $32.3[3.5-294.0]$ & $<10^{-2}$ & $3.6[0.9-13.8]$ & 0.10 \\
\hline December & 40 & 13.4 [1.9-95.3] & 0.01 & $2.6[0.8-7.8]$ & $<10^{-3}$ \\
\hline January & 40 & $14.8[2.2-100.0]$ & $<10^{-2}$ & $7.2[2.3-22.2]$ & 0.43 \\
\hline February & 40 & $7.8[1.0-61.3]$ & 0.05 & $1.7[0.4-7.1]$ & 0.10 \\
\hline \multicolumn{6}{|c|}{ Interaction month*insecticide treatment } \\
\hline August & 40 & 1 & & 1 & \\
\hline September & 40 & $1.0[0.0-51.5]$ & 0.99 & $6.0[0.2-163.0]$ & 0.29 \\
\hline October & 40 & $0.02\left[1.110^{-3}-0.4\right]$ & 0.01 & $2.910^{-3}\left[3.110^{-4}-2.710^{-2}\right]$ & $2.710^{-7}$ \\
\hline November & 40 & $1.910^{-3}\left[8.810^{-5}-0.0\right]$ & $10^{-4}$ & $3.710^{-3}\left[3.710^{-4}-3.610^{-2}\right]$ & $1.510^{-6}$ \\
\hline December & 40 & $1.310^{-3}\left[7.110^{-5}-0.0\right]$ & $10^{-4}$ & $2.010^{-3}\left[2.310^{-4}-1.710^{-3}\right]$ & $1.310^{-8}$ \\
\hline January & 40 & $2.410^{-4}\left[1.510^{-5}-4.010^{-3}\right]$ & $10^{-8}$ & $1.710^{-4}\left[2.010^{5}-1.510^{-3}\right]$ & $6.310^{-15}$ \\
\hline February & 40 & $2.010^{-4}\left[1.110^{-5}-3.510^{-3}\right]$ & $10^{-8}$ & $3.710^{-4}\left[3.710^{-5}-3.710^{-3}\right]$ & $1.910^{-11}$ \\
\hline
\end{tabular}

NS not significative 
Table 4 Univariate analysis of induced mortality against An. arabiensis in houses

\begin{tabular}{|c|c|c|c|c|c|c|c|}
\hline \multirow[t]{2}{*}{ Variables } & \multicolumn{3}{|c|}{ Mud households pre-treatment } & \multicolumn{3}{|c|}{ Mud households post-treatment } & \multirow[t]{2}{*}{ pvalue ${ }^{a}$} \\
\hline & $\mathrm{N}^{\mathbf{b}}$ & Median [IQR] & {$[$ Min-max] } & $\mathbf{N}$ & Median [IQR] & [Min-max] & \\
\hline Treatment & 176 & $0.0[0.0-0.0]$ & {$[0.0-0.4]$} & 616 & $0.9[0.7-1.0]$ & {$[0.0-1.0]$} & $<10^{-15}$ \\
\hline \multicolumn{8}{|l|}{ Site } \\
\hline Ambohitranivo & 80 & $0.0[0.0-0.0]$ & {$[0.0-0.1]$} & 280 & $0.9[0.8-1.0]$ & {$[0.0-1.0]$} & $<10^{-15}$ \\
\hline Saharevo & 96 & $0.0[0.0-0.0]$ & {$[0.0-0.4]$} & 336 & $0.9[0.7-1.0]$ & {$[0.0-1.0]$} & $<10^{-15}$ \\
\hline \multicolumn{8}{|l|}{ Month } \\
\hline June $e^{c}$ & 88 & $0.0[0.0-0.0]$ & {$[0.0-0.1]$} & 0 & - & - & - \\
\hline July & 88 & $0.0[0.0-0.0]$ & {$[0.0-0.4]$} & 0 & - & - & - \\
\hline August & 0 & - & - & 88 & $1.0[1.0-1.0]$ & {$[0.9-1.0]$} & $<10^{-15}$ \\
\hline September & 0 & - & - & 88 & $1.0[1.0-1.0]$ & [0.9-1.0] & $<10^{-15}$ \\
\hline October & 0 & - & - & 88 & $1.0[0.9-1.0]$ & [0.7-1.0] & $<10^{-15}$ \\
\hline November & 0 & - & - & 88 & $0.9[0.9-1.0]$ & [0.6-1.0] & $<10^{-15}$ \\
\hline December & 0 & - & - & 88 & $0.9[0.8-1.0]$ & [0.6-1.0] & $<10^{-15}$ \\
\hline January & 0 & - & - & 88 & $0.7[0.5-0.8]$ & {$[0.1-1.0]$} & $<10^{-15}$ \\
\hline February & 0 & - & - & 88 & $0.3[0.2-0.5]$ & {$[0.0-0.8]$} & $<10^{-15}$ \\
\hline
\end{tabular}

a Comparaison of the distribution of mortality rate was done with Mann-Whitney-Wilcoxon/Kruskall-Walis test

b Effective group

c June and July were considered as reference month for pre- and post-treatment data

Table 5 Univariate analysis of induced mortality against Aedes albopictus in houses

\begin{tabular}{|c|c|c|c|c|c|c|c|}
\hline \multirow[t]{2}{*}{ Variables } & \multicolumn{3}{|c|}{ Mud houses pre-treatment } & \multicolumn{3}{|c|}{ Mud houses post-treatment } & \multirow[t]{2}{*}{ pvalue } \\
\hline & $\mathrm{N}^{\mathrm{b}}$ & Median [IQR] & [Min-max] & $\mathbf{N}$ & Median [IQR] & [Min-max] & \\
\hline Treatment & 176 & $0.0[0.0-0.0]$ & {$[0.0-0.2]$} & 616 & $1.0[0.7-1.0]$ & {$[0.0-1.0]$} & $<2.210^{-16}$ \\
\hline \multicolumn{8}{|l|}{ Site } \\
\hline Ambohitranivo & 80 & $0.0[0.0-0.0]$ & {$[0.0-0.0]$} & 280 & $1.0[0.7-1.0]$ & {$[0.0-1.0]$} & $<2.210^{-16}$ \\
\hline Saharevo & 96 & $0.0[0.0-0.0]$ & {$[0.0-0.2]$} & 336 & $0.9[0.7-1.0]$ & {$[0.0-1.0]$} & $<2.210^{-16}$ \\
\hline \multicolumn{8}{|l|}{ Month } \\
\hline June $e^{c}$ & 88 & $0.0[0.0-0.0]$ & {$[0.0-0.1]$} & 0 & - & - & - \\
\hline July & 88 & $0.0[0.0-0.0]$ & {$[0.0-0.2]$} & 0 & - & - & - \\
\hline August & 0 & - & - & 88 & $1.0[1.0-1.0]$ & {$[0.9-1.0]$} & $<2.210^{-16}$ \\
\hline September & 0 & - & - & 88 & $0.9[0.6-1.0]$ & {$[0.0-1.0]$} & $<2.210^{-16}$ \\
\hline October & 0 & - & - & 88 & $0.4[0.2-0.7]$ & {$[0.0-1.0]$} & $<2.210^{-16}$ \\
\hline November & 0 & - & - & 88 & $0.8[0.3-1.0]$ & [0.0-1.0] & $<2.210^{-16}$ \\
\hline December & 0 & - & - & 88 & $0.9[0.8-1.0]$ & {$[0.2-1.0]$} & $<2.210^{-16}$ \\
\hline January & 0 & - & - & 88 & $1.0[0.8-1.0]$ & {$[0.6-1.0]$} & $<2.210^{-16}$ \\
\hline February & 0 & - & - & 88 & $1.0[1.0-1.0]$ & [0.9-1.0] & $<2.210^{-16}$ \\
\hline
\end{tabular}

a Comparaison of the distribution of mortality rate was done with Mann-Whitney-Wilcoxon/Kruskall-Walis test

b Effective group

c June and July were considered as reference month for pre- and post-treatment data

surfaces is ensured, this study shows that activity of bendiocarb can decline significantly within several months after spraying. It doesn't reflect the purposes of WHO which showed that in many cases IRS of bendiocarb becoming ineffective earlier than the time when they would normally be due for re-spraying.
Chemically induced avoidance behaviors by Malagasy malaria vector mosquitoes should be defined using standardized methods (e.g., excito-repellency boxes and experimental huts) to determine the exact impact of chemicals on malaria transmission and malaria control [25]. Although chemicals used for vector control have 


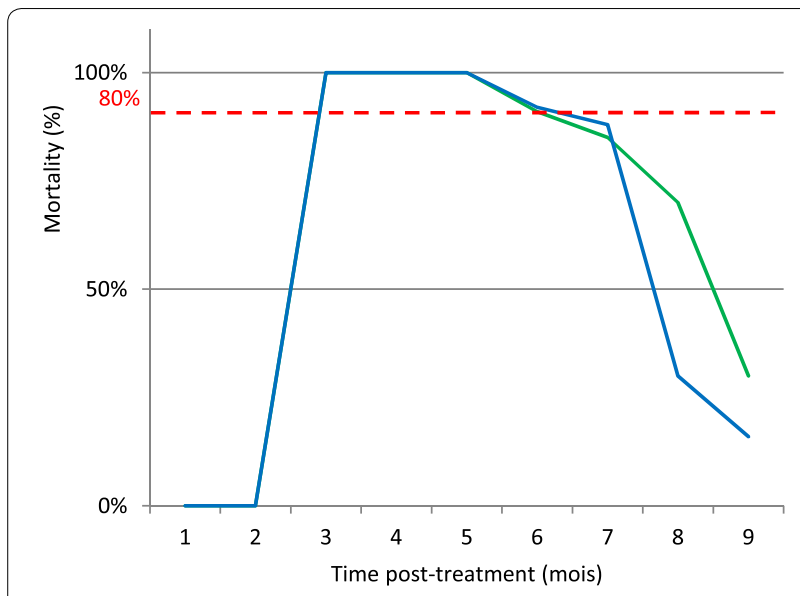

Fig. 4 Comparaison of persistence of bendiocarb on mudwalls houses and experimental huts) against An. arabiensis

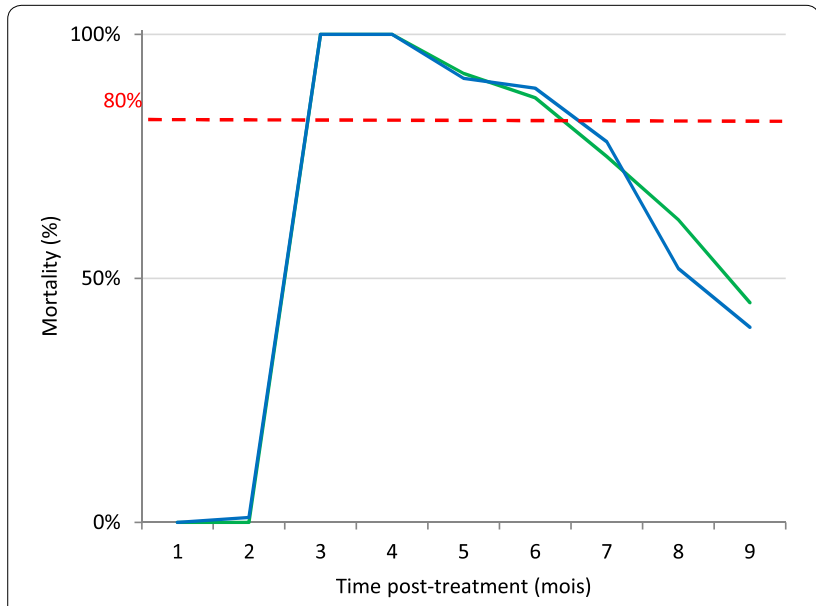

Fig. 5 Comparaison of persistence of bendiocarb on mudwalls houses and experimental huts) against Aedes albopictus historically been evaluated based on toxicity, characterizing the spatial repellent and contact irritant actions of these compounds is a necessity to further the understanding of the mechanism of action of these important public health tools. Such an understanding will help drive innovative methods for disease control using currently available resources as well as aid in the development of novel compounds [26].

The first thoughtfulness to choose the insecticide to be used for IRS is its confirmed effectiveness on the target vector species. It is also crucial to have knowledge of the residual life of insecticide used in IRS program to guess an effectiveness of malaria vector control interventions in Madagascar. Note that IRS in Madagascar is mainly deployed in low-transmission settings and the Deployment of LLIN and IRS may have prevented 100,000 cases annually [27]. Given that the efficacy of bendiocarb decreases below $80 \% 5$ months after treatment, the spraying cycles of bendiocarb may not exceed 5 months to have a protective effectiveness of IRS using bendiocarb in Madagascar.

In this current study, results showed a similarity obtained during bioassay tests performed in experimental huts and in houses made of muds. Indeed, this is the first study in Madagascar which uses experimental huts as tools for insecticide residual life evaluation. Findings resulting from this study validate that experimental huts tool is a perfect tool to make an extrapolation of insecticide bio-efficacy on walls.

\section{Conclusion}

The bendiocarb is effective against Anopheles arabiensis and Aedes albopictus sensitive strain tested in the present study. The residual life of this insecticide on walls made of

Table 6 Comparaison of induced mortality of An. arabiensis in mud experimental huts and in mud houses

\begin{tabular}{|c|c|c|c|c|c|c|c|}
\hline \multirow[t]{2}{*}{ Month } & \multicolumn{3}{|c|}{ Experimental huts-mud wall } & \multicolumn{3}{|c|}{ Houses-mud wall } & \multirow[t]{2}{*}{$p$ value } \\
\hline & $\mathbf{N}$ & Median [IQR] & {$[$ Min-max] } & $\mathbf{N}$ & Median [IQR] & [Min-max] & \\
\hline August & 8 & $1.0[1.0-1.0]$ & {$[1.0-1.0]$} & 88 & $1.0[1.0-1.0]$ & {$[0.9-1.0]$} & 0.61 \\
\hline September & 8 & $1.0[1.0-1.0]$ & {$[1.0-1.0]$} & 88 & $1.0[1.0-1.0]$ & {$[0.9-1.0]$} & 0.61 \\
\hline October & 8 & $1.0[1.0-1.0]$ & {$[0.9-1.0]$} & 88 & $1.0[0.9-1.0]$ & {$[0.7-1.0]$} & 0.64 \\
\hline November & 8 & $0.9[0.9-0.9]$ & {$[0.1-1.0]$} & 88 & $0.9[0.9-1.0]$ & {$[0.6-1.0]$} & 0.84 \\
\hline December & 8 & $0.9[0.8-1.0]$ & {$[0.4-1.0]$} & 88 & $0.9[0.8-1.0]$ & {$[0.6-1.0]$} & 1.00 \\
\hline January & 8 & $0.3[0.2-0.4]$ & {$[0.2-0.7]$} & 88 & $0.7[0.5-0.8]$ & {$[0.1-1.0]$} & 0.0007 \\
\hline February & 8 & $0.2[0.1-0.2]$ & {$[0.0-0.3]$} & 88 & $0.3[0.2-0.5]$ & {$[0.0-0.8]$} & 0.009 \\
\hline
\end{tabular}


Table 7 Comparaison of induced mortality of Aedes albopictus in mud experimental huts and in mud houses

\begin{tabular}{|c|c|c|c|c|c|c|c|}
\hline \multirow[t]{2}{*}{ Month } & \multicolumn{3}{|c|}{ Experimental huts-mud wall } & \multicolumn{3}{|c|}{ Houses-mud wall } & \multirow[t]{2}{*}{$p$ value } \\
\hline & $\mathbf{N}$ & Median [IQR] & {$[$ Min-max] } & $\mathrm{N}$ & Median [IQR] & [Min-max] & \\
\hline August & 8 & $1.0[1.0-1.0]$ & {$[0.9-1.0]$} & 88 & $1.0[1.0-1.0]$ & {$[0.9-1.0]$} & 0.69 \\
\hline September & 8 & $1.0[1.0-1.0]$ & {$[0.9-1.0]$} & 88 & $1.0[1.0-1.0]$ & {$[0.9-1.0]$} & 0.69 \\
\hline October & 8 & $0.8[0.8-0.8]$ & {$[0.6-0.9]$} & 88 & $1.0[0.9-1.0]$ & {$[0.6-1.0]$} & $<10^{-3}$ \\
\hline November & 8 & $0.7[0.6-0.8]$ & {$[0.5-1.0]$} & 88 & $0.9[0.8-0.9]$ & {$[0.2-1.0]$} & 0.006 \\
\hline December & 8 & $0.6[0.5-0.7]$ & {$[0.1-1.0]$} & 88 & $0.9[0.6-1.0]$ & {$[0.0-1.0]$} & 0.04 \\
\hline January & 8 & $0.1[0.0-0.2]$ & {$[0.0-0.3]$} & 88 & $0.8[0.3-1.0]$ & {$[0.0-1.0]$} & $<10^{-3}$ \\
\hline February & 8 & $0.1[0.0-0.1]$ & {$[0.0-0.2]$} & 88 & $0.5[0.2-0.7]$ & {$[0.0-1.0]$} & $<10^{-3}$ \\
\hline
\end{tabular}

mud in experimental huts and in the village has the same duration. This finding reflects that experimental huts in Madagascar are perfect tool to evaluate the residual life of insecticide used in spraying.

\section{Abbreviations}

DDT: dichlorodiphenyltrichloroethane; IRS: insecticide residual spraying; ITN: insecticide-treated nets; IQR: inter-quartile range; NMCP: National Malaria Control Programme; WHO: World Health Organization.

\section{Authors' contributions}

SR and SB conceived the study. SR and TNJJN acquired the bioassay data. JA and YM did the statistical analysis. SR, TNJJN, YM and SB drafted the paper and all coauthors contributed to the critical revision and development of intellectual content. All authors read and approved the final manuscript.

\section{Author details}

${ }^{1}$ Unité d'Entomologie Médicale, Institut Pasteur de Madagascar, BP 1274 , Antananarivo, Madagascar. ${ }^{2}$ Ecole Doctorale Sciences de la Vie et de I'Environnement, Université d'Antananarivo, Antananarivo, Madagascar. ${ }^{3}$ Unité d'Epidémiologie des Maladies Emergentes, Institut Pasteur, 25-28, rue du Docteur Roux, 75015 Paris, France.

\section{Acknowledgements}

This study was supported by the Institut Pasteur de Madagascar (IPM). Professor Christophe Rogier, Director of the Institut Pasteur de Madagascar during the study, is warmly thanked. Authors are grateful to the inhabitants of the studied area for their cooperation during bioassay tests. We thank mosquito collectors from Moramanga and staff from the Medical Entomology Unit of the IPM for their kind support and collaboration. We are grateful to the Malagasy NMCP for insecticide providing and spraying.

\section{Competing interests}

The authors declare that they have no competing interests.

Received: 5 December 2015 Accepted: 14 May 2016

Published online: 26 May 2016

\section{References}

1. Sharp BL, Le Sueur D, Bekker P. Effect of DDT on survival and blood feeding success of Anopheles arabiensis in northern KwaZulu, Republic of South Africa. J Am Mosqu Contr Assoc. 1990;6:197-202.

2. WHO. WHO position statement on integrated vector management. Wkly Epidemiol Rec. 2008:20:177-84.

3. Beier JC, Keating J, Githure JI, Macdonald MB, Impoinvil DE, Novak RJ. Integrated vector management for malaria control. Malar J. 2008;7:S4.
4. Chanda E, Masaninga F, Coleman M, Sikaala C, Katebe C, MacDonald M, et al. Integrated vector management: the Zambian experience. Malar J. 2008;7:164

5. Zaim M, Aitio A, Nakashima N. Safety of pyrethroid-treated mosquito nets. Med Vet Entomol. 2000;14:1-5.

6. Kelly-Hope L, Ranson H, Hemingway J. Lessons from the past: managing insecticide resistance in malaria control and eradication programmes. Lancet Infect Dis. 2008;8:387-9.

7. WHO. Pesticides and their application: for the control of vectors and pests of public health importance. Geneva: World Health Organization; 2006.

8. Akogbeto M, Padonou G, Bankolé H, Kindé GD, Gbedjissi G. Dramatic decline of malaria transmission after implementation of large-scale Indoor Residual Spraying using bendiocarb in Bénin, West Africa, an area of high Anopheles gambiae resistance to pyrethroids. Am J Trop Med Hyg. 2011;85:586-93.

9. Ossè R, Aikpon R, Padonou GG, Oussou O, Yadouléton A, Akogbeto M. Evaluation of the efficacy of bendiocarb in indoor residual spraying against pyrethroid resistant malaria vectors in Benin: results of the third campaign. Parasite Vectors. 2012;5:163.

10. Tangena JA, Adiamoh M, D’Alessandro U, Jarju L, Jawara M, Jeffries D, et al. Alternative treatments for indoor residual spraying for malaria control in a village with pyrethroid-and DDT-resistant vectors in the Gambia. PLoS ONE. 2013;8:e74351.

11. Ansari MA, Razdan RK. Impact of residual spraying of bendiocarb against the malaria vector Anopheles culicifacies in selected villages of the Ghaziabad District, Uttar Pradesh, India. J Am Mosqu Contr Assoc. 2004;20:418-23.

12. Etang J, Nwane P, Mbida JA, Piameu M, Manga B, Souop D, et al. Variations of insecticide residual bio-efficacy on different types of walls: results from a community-based trial in south Cameroon. Malar J. 2011;10:333.

13. Corbett JR, Wright R, Baille AC. The biochemical mode of action of pesticides. 2nd ed. New York: Academic Press; 1984.

14. WHO. Recommended insecticides for indoor residual spraying against malaria vectors. Geneva: World Health Organization; 2009.

15. WHO. Indoor Residual Spraying: An operational manual for indoor residual spraying (IRS) for malaria transmission control and elimination. Geneva: World Health Organization; 2013.

16. R Core Team. R: A language and environment for statistical computing. In: Foundation for Statistical Computing. Vienna; 2013.

17. Giga DP. Jane Canhao, S. Relative toxicity and persistence of pyrethroid deposits on different surfaces for the control of Prostephanus truncates and Sitophilus zeamais. J Stored Prod Res. 1991;27:153-60.

18. Mpofu SM, Kanyimo KH, Masendu H. Potential use of bendiocarb (Ficam VC) for malaria control in an area of Zimbabwe. J Am Mosqu Contr Assoc. 1991;7:536-42.

19. Maharaj R, Casimiro S, Mthembu SD, Sharp BL. The residual life of bendiocarb: a field-based evaluation from Mozambique. J Med Entomol. 2004:41:130-2.

20. Asinas CY, Hugo CT, Boase CJ, Evans RG. Evaluation of selective spraying of bendiocarb (Ficam VC) for the control of Anopheles flavirostris in the Philippines. J Am Mosqu Contr Assoc. 1994;10:496-500. 
21. Santos R, Fayal A, Aguiar A, Vieira D, Povoa MM. [Evaluation of the residual effect of pyrethroids on Anopheles in the Brazilian Amazon](in Protuguese). Rev Saúde Pública. 2007;41:276-83.

22. Djènontin $A$, Aïmihouè $O$, Sèzonlin $M$, Damien $G B$, Ossè $R$, Soukou $B$, et al. The residual life of bendiocarb on different substrates under laboratory and field conditions in Benin, Western Africa. BMC Res Notes. 2013;6:458.

23. Protopopoff N, Matowo J, Malima R, Kavishe R, Kaaya R, Wright A, et al. High level of resistance in the mosquito Anopheles gambiae to pyrethroid insecticides and reduced susceptibility to bendiocarb in north-western Tanzania. Malar J. 2013;12:149.

24. Akogbeto M, Padonou G, Gbenou D, Irish S, Yadouleton A. Bendiocarb, a potential alternative against pyrethroid resistant Anopheles gambiae in Benin, West Africa. Malar J. 2010;9:204.
25. Roberts DR, Alecrim WD, Hshish P, Grieco JP, Bangs M, Andre RG, et al. A probability model of vector behavior effects of DDT repellency, irritancy, and toxicity in malaria control. J Vector Ecol. 2000;25:48-61.

26. Achee NL, Sardelis MR, Dusfour I, Chauhan KR, Grieco JP. Characterization of spatial repellent, contact irritant, and toxicant chemical actions of standard vector control compounds. J Am Mosquito Contr. 2009;25:156-67.

27. Kesteman T, Randrianarivelojosia M, Raharimanga V, Randrianasolo L, Piola P, Rogier C. Effectiveness of malaria control interventions in Madagascar: a nationwide case_control survey. Malar J. 2016;15:1.

\section{Submit your next manuscript to BioMed Central and we will help you at every step:}

- We accept pre-submission inquiries

- Our selector tool helps you to find the most relevant journal

- We provide round the clock customer support

- Convenient online submission

- Thorough peer review

- Inclusion in PubMed and all major indexing services

- Maximum visibility for your research

Submit your manuscript at www.biomedcentral com/submit 